\title{
JOSEP GODAY E O MOBILIÁRIO ESCOLAR ESPANHOL NA PRIMEIRA METADE DO SÉCULO 201
}

DOI: http://dx.doi.org/10.1590/2236-3459/46618

\author{
Jauri dos Santos Sá \\ Universidade do Vale do Rio dos Sinos, Brasil.
}

\section{$\cos 80$}

\begin{abstract}
Resumo mobiliário que procura dignificar a sala aula para além dos aspectos arquitetônicos e estéticos.

Palavras-chave: cultura material escolar, arquitetura escolar, mobiliário escolar.

\section{JOSEP GODAY AND SPANISH SCHOOL FURNITURE DURING THE FIRST HALF OF THE 20TH CENTURY}

Neste artigo estão sistematizadas reflexões sobre a história do mobiliário escolar espanhol, com foco nas propostas do arquiteto Josep Goday i Casals. Inserido no campo de estudo do patrimônio educativo, busca-se enxergar o mobiliário escolar como autêntica fonte de investigação da cultura material escolar. A base metodológica da análise situa-se no campo da pesquisa exploratória e o procedimento assume a forma de pesquisa bibliográfica. A coleta de dados realizou-se no acervo do Centro de Educação Infantil e Primária Ramon Llull e na obra Josep Goday Casals: arquitectura escolar a Barcelona de la Mancomunitat a la república (2008). Nas conclusões, enfatiza-se o papel desempenhado pelo arquiteto como protagonista na configuração de um

\begin{abstract}
The present paper presents some systematic reflections on the history of Spanish school furniture, focusing on the proposals idealized by architect Josep Goday i Casals. Inserted in the field of study of educational patrimony, it seeks to see school furniture as an authentic source to investigate the material culture of the school. The methodological basis of the analysis is situated in the field of exploratory research, and is done in the form of research on literature. Data is obtained from the collection of the Ramon Llull Center of Infant and Elementary Education (Centro de Educação Infantil e Primária Ramon Llull) and in the work Josep Goday Casals: arquitectura escolar a Barcelona de la Mancomunitat a la república (2008). In the conclusions the role played by architect Goday is emphasized, as a protagonist in the configuration of furniture that tries to dignify the classroom, besides the architectural and esthetic aspects.

Keywords: material culture of the school, school architecture, school furniture, Josep Goday.
\end{abstract}

\footnotetext{
${ }^{1}$ Este trabalho foi realizado com apoio do Conselho Nacional de Desenvolvimento Científico e Tecnológico CNPq/Brasil, modalidade pós-doutorado júnior. 


\section{JOSEP GODAY E O MOBILIARIO ESCOLAR ESPANHOL NA PRIMEIRA METADE DO SÉCULO 20}

\section{Resumen}

En este artículo están sistematizadas reflexiones sobre la historia del mueble escolar español con especial atención a las propuestas del arquitecto Josep Goday i Casals. Inscrita en el campo de estudio del patrimonio educativo, busca mirar el mueble escolar como fuente auténtica de la investigación de la cultura material escolar. La base metodológica del análisis reside en el campo de la investigación exploratoria y el procedimiento tómala forma de investigación bibliográfica. La recopilación de datos se lleva a cabo en la colección del Centro de Educación Infantil y Primaria Ramón Llull y en el libro Josep Goday Casals: arquitectura escolar a Barcelona de la Mancomunitat a la República (2008). Las conclusiones hacen hincapié en el papel del arquitecto como el protagonista en la configuración del mueble escolar que procura dignificar el aula más allá de los aspectos arquitectónicos y estéticos.

Palabras-clave: cultura material escolar; arquitectura escolar, mueble escolar.

\section{JOSEP GODAY ET LE MOBILIER SCOLAIRE ESPAGNOL DANS LA PREMIĖRE MOTIÉ DU $20^{\mathrm{E} M E}$ SIĖCLE}

\section{Résumé}

Dans cet article sont des réflexions systématiues sur l'histoire du mobilier scolaire espagnol, dans l'approche des propositions de l'architecte Josep Goday i Casals. Inseré dans le domaine de l'étude du patrimoine éducatif, il cherche à voir le mobilier scolaire comme une source authentique d'investigation de la culture matérielle scolaire. La base méthodologique de l'analyse se place dans le domaine de la recherche exploratoire et la procedure prend la forme de recherche bibliographique. La collecte de données se fait dans le du Centre d'Éducation Infantile Ramon Llull et dans l'oeuvre Josep Goday Casals: arquitectura escolar a Barcelona de la Mancomunitat a la República (2008). Dans les conclusions, nous faisons remarquer le rôle joué par l'architecte comme protagoniste dans la configuration d'un mobilier qui cherche à dignifier la salle de classe en dehors des aspects architectoniques et esthétiques.

Mots-clé: culture matérielle scolaire, architecture scolaire, mobilier scolaire. 


\section{Introdução}

nserido no campo de estudo do patrimônio educativo e da cultura material escolar, o presente trabalho tem como propósito investigar a história do mobiliário escolar espanhol enquanto componente de uma modernidade pedagógica ${ }^{2}$ que procurava atenuar as duras condições das instalações escolares na primeira metade do século 20. A partir das realizações do arquiteto catalão Josep Goday i Casals para um grupo de escolas públicas construídas na cidade de Barcelona, reflexionamos sobre a valorização do profissional arquiteto que, junto com o pedagogo Manuel Ainaud i Sanchéz ${ }^{3}$, trilhou os caminhos da escola pública municipal barcelonesa ${ }^{4}$.

A partir da Revolução Industrial a Catalunha viveu um período de grande prosperidade econômica, cultural e política. Paralelamente a estas transformações sociais a cidade de Barcelona, em particular, viveu uma intensa evolução demográfica. Um relatório municipal publicado em 1903 revela a necessidade urgente da construção de edifícios escolares, medida que procurava resolver a crescente demanda por vagas. As aspirações foram concretizadas em 1916 com a construção de uma série de edifícios escolares, num período que ficou conhecido como um dos mais produtivos em termos de políticas educacionais.

Nessa produção foi incluída uma nova tipologia, a do mobiliário escolar. O mobiliário, geralmente, procede do encargo oficial da administração, que por seu custo não resulta fácil de substituir durante uma ou várias gerações. Investigar esse patrimônio educativo significa buscar, em um dos elementos chave da cultura material escolar, dados sobre controle, disciplina e manejo dos corpos em sala de aula, além de proporcionar uma valiosa informação respeito ao seu desenho, construção e usos.

A crescente atenção dedicada pelos historiadores da educação à cultura material da escola transformou os espaços escolares em uma parte importante do patrimônio histórico-educativo. Segundo Viñao Frago (2008), o espaço escolar passou a ser visto como um depósito onde, com maior ou menor fortuna, se produz, se conserva ou se destrói esse patrimônio. Um patrimônio formado não só pelos edifícios, mas também

\footnotetext{
${ }^{2}$ A crise espanhola de 1898 serviu como estímulo para que se buscasse um novo ambiente educativo. Surgiram no país instituições emblemáticas que pretendiam acabar com o isolamento científico, educativo e cultural, bem como promover a modernização pedagógica da Espanha na virada do século. Na Catalunha destacaram-se propostas da iniciativa pública e da privada. A pública, por exemplo, incorporou em seu plano de atuação o movimento higienista europeu, promovido por médicos arquitetos e pedagogos. Também floresceram escolas privadas, ligadas nomes como Rosa Sensat, Alexandre Galí, Pau Vila, Joan Palau Vera, Manuel Ainaud e Artur Martorell, materializadas na experiência de instituições como a Escola Moderna de Ferrer Guardia (1901), o Ateneu Enciclopédico Popular (1903), a Escola Horaciana de Pau Vila (1905) e a Escola de Mestres (1906). Ver Pericacho Gómez (2014).

${ }^{3}$ Manuel Ainaud iniciou sua vida no mundo da educação em 1908, como professor de Desenho na Escola Horaciana, fundada e dirigida por Pau Vila, em Barcelona. Estudou a problemática escolar e propôs algumas alternativas à situação que se encontrava a escola pública municipal. Em 1917 foi nomeado chefe da Assessoria Técnica da Comissão de Cultura da Prefeitura de Barcelona, integrada por três seções: a arquitetônica, dirigida por Josep Goday i Casals, a médica, dirigida pelo pediatra Enrique Mias e a pedagógica, dirigida por Ainaud. Para mais dados ver Domènech (1997).

${ }^{4} \mathrm{Na}$ Espanha as pesquisas sobre arquitetura escolar tiveram impulso a partir de 1985, com a publicação do ensaio de Jaume Trillha sobre o espaço social e material da escola. No entanto, foi a partir de 1994 que as pesquisas se desenvolvem, graças a publicação do número duplo da revista Historia de la Educación, organizada por Antonio Viñao Frago e consagrada ao tema do espaço escolar. Para mais dados ver Châtelet (2006).
} 
pelos mais diversos objetos procedentes do interior escolar - livros, material didático, mobiliário, etc. - ou produzidos no meio escolar - exames de alunos, diários escolares, fotografias, diplomas.

Os estudos de Antonio Viñao Frago (2012) revelam, também, que a análise da cultura material das instituições educativas se constitui em um campo historiográfico em auge. Porém, o autor alerta para uma série de questões e problemas, sobretudo, quanto a enfoque, fontes e metodologias, advertindo para o perigo de reduzir a investigação a uma coleção de detalhes. Para Abreu Jr. (2005), esse é um campo de pesquisa de natureza complexa e multidisciplinar, pois abrange a história da educação, assim como a antropologia, a sociologia e a pedagogia, ao qual incluo a arquitetura, pois nesse contexto lidamos com distintos materiais, tais como os edifícios, mobiliário e até mesmo outros objetos bem pouco sofisticados, ou seja, a cultura material escolar se manifesta não só nesses objetos, mas nas práticas empreendidas por meio deles.

Buscando enxergar no mobiliário escolar uma autêntica fonte de investigação da cultura material escolar, problematizamos no papel desempenhado pelo arquiteto Goday o protagonista na configuração de um mobiliário que procurava dignificar a sala de aula para além dos aspectos arquitetônicos e estéticos, integrando os elementos funcionais com os pedagógicos.

\section{Josep Goday e o programa de construções escolares}

O estímulo definitivo em matéria de educação na Espanha se produziu a partir de 1900, com a criação do Ministério de Instrução Pública e Belas Artes. No entanto, foi com o real decreto de 1904 que se faz referência, pela primeira vez, às escolas graduadas. No caso da cidade de Barcelona, a prefeitura optou por construiu um pequeno modelo de sistema educativo autônomo, com suas próprias escolas e serviços. As iniciativas mais importantes verificadas dizem respeito à construção de escolas públicas de caráter unitário, geralmente edifícios de planta baixa, ou duas plantas, sólidos e bem construídos.

Esse dinamismo municipal recebeu um impulso a partir de 1906 ao incorporar, em seu plano de atuação, o movimento higienista europeu, promovido por médicos, arquitetos e pedagogos criando, pelas instituições complementares, as colônias escolares e os jardins de infância. Com o regime de vida ao ar livre buscava-se equilibrar condições de vida pouco saudáveis, que afetavam a maioria da população em idade escolar em uma Barcelona ainda em processo de industrialização. Esse movimento culminou em 1912, quando a prefeitura convocou um concurso de escolas. O objetivo era obter projetos que deveriam adaptar-se as especiais características das quadras do distrito do Eixample ${ }^{5}$ barcelonês.

Também nessa etapa mereceu destaque a criação do Conselho de Investigação Pedagógica (1913), que organizou a primeira escola de verão, com estreita colaboração com os movimentos higienistas e de renovação pedagógica. Tais gestões foram rematadas 1914 com a criação da Escola do Bosque, primeira escola ao ar livre de

\footnotetext{
${ }^{5}$ Em 1854 uma Ordem Real permitiu a derrubada das muralhas da cidade de Barcelona e em 1859 foi aprovado o projeto do engenheiro Ildefonso Cerdà para ocupar a área de plantio existente entre a antiga cidade amuralhada e os municípios limítrofes. O plano de Cerdà consistia em uma quadrícula sobre a qual dominava uma malha de ruas paralelas e perpendiculares, unicamente rompida por duas grandes avenidas que atravessam a trama diagonalmente. Ver Sá (2012). 
Barcelona e da Espanha. Com a construção da Escola do Bosque no parque de Montjuic, começou uma série de edificações escolares em Barcelona de grande interesse social, arquitetônico e urbano (Sá, 2012).

Em 1916 a Prefeitura de Barcelona criou a Comissão de Cultura e, em 1917, a Assessoria Técnica dessa comissão, órgão responsável pela concepção do plano de distribuição dos grupos escolares municipais. A frente da assessoria técnica estava o arquiteto Josep Goday i Casals que, trabalhando em sintonia com o projeto pedagógico de Manuel Ainaud i Sanchéz, planificou um novo modelo de edifício escolar. Nesse mesmo ano, a Assessoria Técnica promoveu uma viagem de estudos que incluiu Genebra, Berna, Basileia, Zurique, Munique, Dresden e Berlim ${ }^{6}$.

É sabido que Berlim foi seu modelo e referência, porém, foi em Munique, cidade do pedagogo Georg Kerschensteiner (1852-1932) e dos arquitetos Karl Hocheder (18541917) e Theodor Fischer (1862-1938), que Goday foi buscar novas ideias. Além disso, não se pode esquecer a Suíça e seu sistema escolar, recopilado no livro Les constructions scolaires en Suisse, de Henri Baudin ${ }^{7}$, publicado em 1907 e que Goday conhecia de primeira mão. O itinerário permitiu aos integrantes da comissão conhecer os resultados da parceria arquitetura-pedagogia, assim como as exigências que os novos caminhos pedagógicos trilhavam. A partir daí, Goday começou a forjar os monumentais edifícios escolares.

Entre 1918 e 1923 Goday projetou todos os edifícios escolares que a Comissão de Cultura construiu: o grupo escolar Baixeras, e a escola infantil de Vallarca, iniciados ambos em 1917, e os grupos escolares Lluis Vives, Mila i Fontanals e Lluisa Cura, Ramón Llull e Pere Vila i Codina, figura 1, projetados em $1919^{8}$. Durante a ditadura de Primo de Rivera (1923-1930) interrompeu seu trabalho, retomado com a chegada da República. Não tardou para as notícias sobre a nova Barcelona pedagógica ${ }^{9}$ cruzar fronteiras por artigos publicados nas mais importantes revistas de arquitetura da época.

${ }^{6}$ A realização das viagens pedagógicas era uma prática comum. Professores ou funcionários do governo, dos vários níveis ou instituições de ensino, examinavam os progressos da instrução nos países estrangeiros. No Brasil, um dos exemplos foi à viagem realizada, em 1891, pelo professor Luiz Augusto dos Reis a Portugal, Espanha, França e Bélgica.

${ }^{7}$ Henri Baudin esboçou, na introdução de sua obra, a história da educação na Suíça, detalhando os locais e a arquitetura das escolas, dando uma atenção especial a temas fundamentais como a área, iluminação e ventilação das salas (Châtelet, 2006, p. 8).

${ }^{8}$ Diversos atores sociais, políticos e econômicos atuaram na implantação dos grupos escolares na cidade de Barcelona. Além do financiamento público, algumas escolas foram edificadas, total ou parcialmente, graças a doações de cidadãos catalães que fizeram fortuna na América Latina, daí a homenagem de batizar com seus nomes as escolas. No Brasil, conforme Marcílio (2005), a prática de batizar os novos grupos escolares com nomes de personalidades, iniciada em 1896 com Bernadinho de Campos na presidência do Estado de São Paulo, revelou-se mais como uma forma de homenagear os amigos, os familiares ou a si próprio, em detrimento de vultos históricos. Ainda segundo Marcílio (2005), poucos cidadãos tiveram seus nomes perpetuados nas escolas em troca da ajuda financeira para a construção dos novos edifícios.

9 Em artigo publicado em 1997, o arquiteto catalão Oriol Bohigas, contextualizando a nova Barcelona pedagógica, diz que a obra da Prefeitura de Barcelona dos anos vinte se fez desde o impulso da pedagogia, enquanto a obra feita pelo governo da Catalunha dos anos oitenta se fez desde o estímulo da arquitetura. (Bohigas, 1997).

Hist. Educ. [Online]

n. 46

Maio/ago., 2015

p. $187-199$ 
Figura 1 -

Arquitetura monumental barcelonesa nos projetos escolares de Josep Goday.
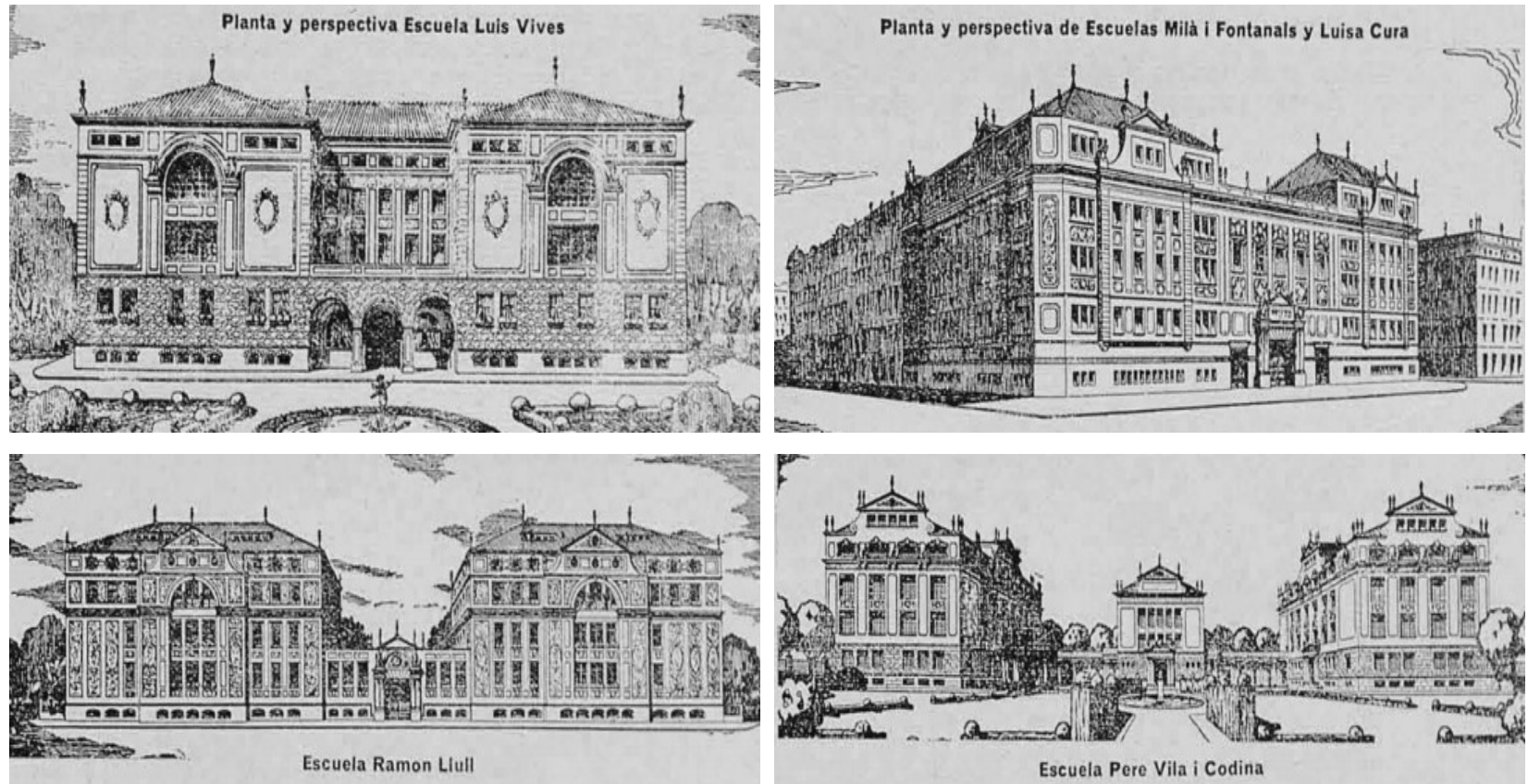

Fonte: Revista Cuadernos de Arquitectura, n. 35, 1959, p. 11.

Por volta de 1925, quando já havia concluído uma notável serie de edifícios, Goday empreendeu outra viagem de estudos, desta vez pela Escandinávia, seguramente muito proveitosa, pois no seu retorno, projetou o Grupo Escolar Collasso i Gil (1934), com clara influência da arquitetura nórdica. O arquiteto catalão, nascido em 1882 e falecido em 1936, que se dedicou quase que exclusivamente a arquitetura escolar, foi também coautor do projeto do edifício sede dos Correios de Barcelona (1914) e autor do projeto de vários outros edifícios, como a singular construção do Pavilhão da Cidade de Barcelona para a Exposição Internacional de 1929. Destacou-se, também, na arquitetura religiosa, distinguindo-se a reforma do Monastério de Sant Pau de Camp, a restauração e ampliação da Igreja de Jesus Maria de Grácia e o concurso para a Igreja do Sagrado Coração de Maria de Buenos Aires (Argentina).

\section{O mobiliário dos grupos escolares}

Em 1905 foram publicadas em Espanha as instruções técnico-higiênicas relativas à construção de escolas, englobando prescrições referentes a projetos para escolas destinadas a alunos de nível primário. A normativa contemplava: localização, orientação, extensão (terreno e edifício), construção, salas, aulas, ventilação, iluminação, calefação e móveis escolares. A respeito desse item, a norma era bastante restrita e mencionava apenas mesas-bancos segundo o número e altura dos alunos. 
Esse mobiliário era ofertado nos catálogos de material para o ensino, que foram publicados na Espanha entre 1881 e 1958, destacando-se os modelos impulsados pelo Museu Pedagógico Nacional - MPN ${ }^{10}$. Partindo de um exemplar projetado para as escolas de Paris, a equipe do MPN desenhou, em 1913, duas propostas oficiais para as escolas espanholas, uma mesa-banco para dois alunos e outra individual (figura 2). Presentes nos catálogos praticamente até o inicio da segunda metade do século 20 , os modelos foram comercializados em múltiplas versões.

Figura 2 -

Mesa-banco para dois alunos e individual. Museu Pedagógico Nacional.
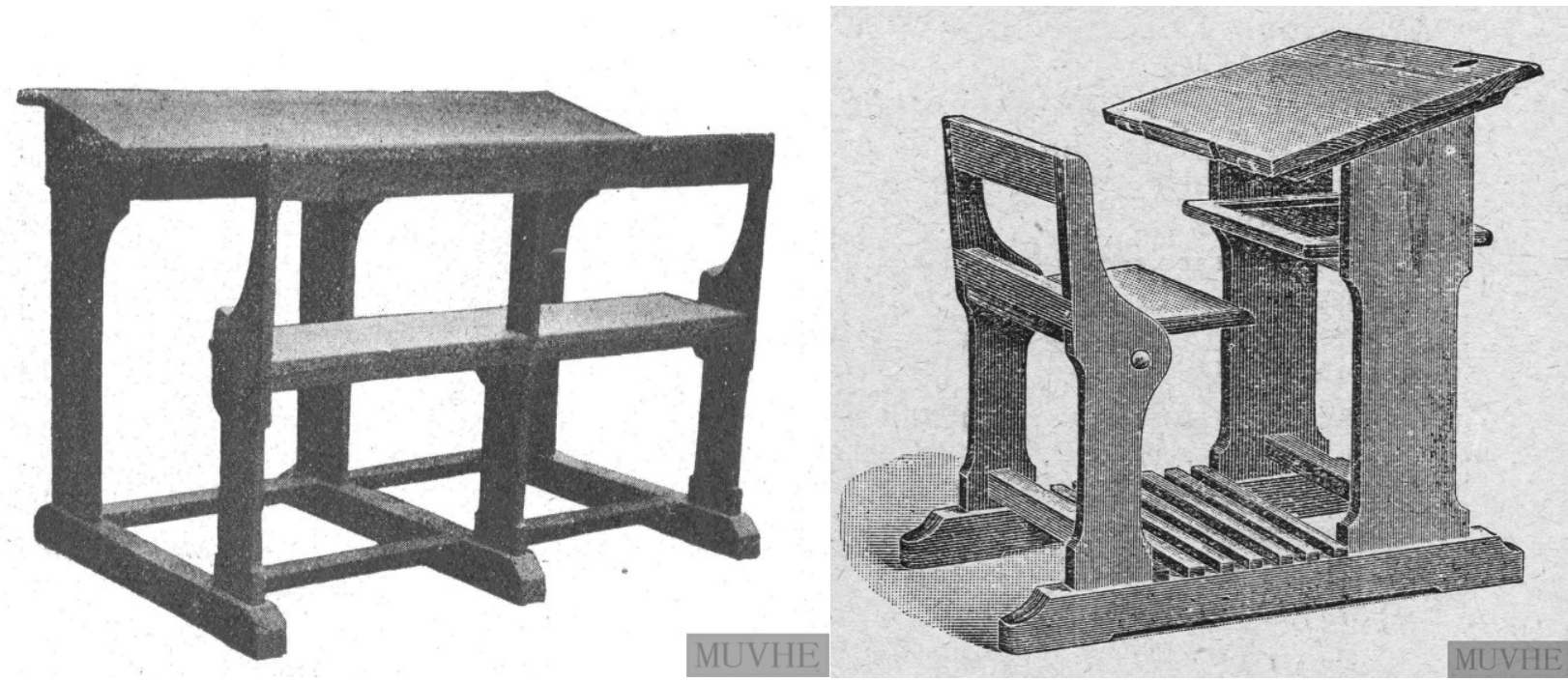

Fonte: Museo Virtual de Historia de la Educación. Universidad de Murcia - www.um.es/muvhe.

Já em Barcelona, Goday mantinha um duplo compromisso com a Prefeitura. Além de projetar os edifícios, foi o responsável pelos estudos das necessidades próprias das escolas ${ }^{11}$, desenhando parte do mobiliário. Com um conhecimento preciso a respeito de materiais, construção e acabamento de móveis, o arquiteto dominava o sistema construtivo, assim como as técnicas e os processos usados nos acabamentos dos móveis de madeira (Pascual, 2008). Seus projetos arquitetônicos eram acompanhados de uma lista detalhada com a quantidade de móveis necessária para cada escola.

Goday estabelecia quatro grandes grupos de móveis: armários do departamento de banho, aulas, salas de coleção e materiais e decoração em geral. Nos memoriais constavam: no primeiro grupo: bancos e tiras de madeira com ganchos para roupa, tudo em madeira de pinho tingida e envernizada. No segundo grupo, o das aulas de educação infantil, a lista era composta: por mesas de quatro lugares, para as crianças menores $(47 \mathrm{~cm})$ e para as maiores $(50 \mathrm{~cm})$; cadeiras proporcionais às medidas das mesas e

\footnotetext{
${ }^{10}$ O Museu Pedagógico Nacional foi criado por decreto lei em 1882. Ativo até 1941 foi bastante influente na renovação da escola espanhola, aglutinando a maior parte das pessoas e dos movimentos que tentaram aproximar à educação as novas exigências científicas e sociais. A biblioteca e o arquivo do Museu Pedagógico Nacional foram doados ao Centro de Documentação da Residência dos Estudantes em 1987 e estão disponíveis para consulta em www.residencia.csic.es.

${ }^{11} \mathrm{Em}$ recente artigo Bencostta (2013) estudou a participação da arquitetura no mundo da educação. TrabaIhando a questão do desenho do mobiliário escolar, concentrou sua análise na primeira metade do século 20 e no papel desempenhado por alguns arquitetos franceses. 
armários de três portas para o material. Para as aulas especiais - desenho - e as dependências diversas - sala de professores, biblioteca, etc. -, o mobiliário era composto por cadeiras, que por suas características e tipologia, também se situavam nos vestíbulos e corredores.

Seguia a lista de mobiliário para as salas de aulas, mesas de quatro lugares e cadeiras proporcionais às mesas. Para os mestres, mesas com gavetas e cadeiras com braços, dois tipos de armários e mesas para usos diversos, com os pés torneados ou com os pés dobráveis. A lista também compreendia os móveis para a sala do diretor e as salas de professores - havia duas. Para a direção: mesa de trabalho, mesa auxiliar, móvel fichário, armário livraria e roupeiro. Para a sala dos professores e biblioteca: armários, semelhantes aos anteriores, e para finalizar, cavaletes para desenho e quadros-negros.

No grupo seguinte, a sala de coleções e material, o mobiliário era composto por: mesinhas dobráveis para trabalhos diversos, armários para coleções e distintas faixas de madeira com ganchos para roupa. Por fim, o item Decoração em geral oferecia uma valiosa informação sobre a decoração da escola: aulas, biblioteca, direção, sala dos professores, vestíbulos e dependências diversas. Efetivamente, as escolas estavam ricamente decoradas, por meio de reproduções de esculturas e relevos clássicos, de gravuras a cores ou fotografias de monumentos ou obras clássicas de pintura e peças de cerâmica.

\section{O mobiliário e as tipologias}

Grande parte do mobiliário escolar projetado por Goday se conservou e está atualmente em uso nas escolas, figura 3, como podemos observar nas imagens do Centro de Educação Infantil e Primária Ramón Llull. Numa primeira aproximação à obra do arquiteto como projetista de móveis, Pascual (2008) estabeleceu três tipologias, que se distribuíam nas distintas escolas. Cada uma das tipologias é consequência de uma época, ainda que o surgimento de uma nova tipologia não significou o desaparecimento da anterior. Como característica, observa-se uma tendência à simplicidade e a depuração decorativa nos projetos. Além disso, as propostas compartem entre si um sentido funcional e prático, ou seja, são móveis bem construídos, sólidos e pensados para durar.

Figura 3 -

Circulação do Ceip Ramon Llull, onde se observam alguns móveis de época.

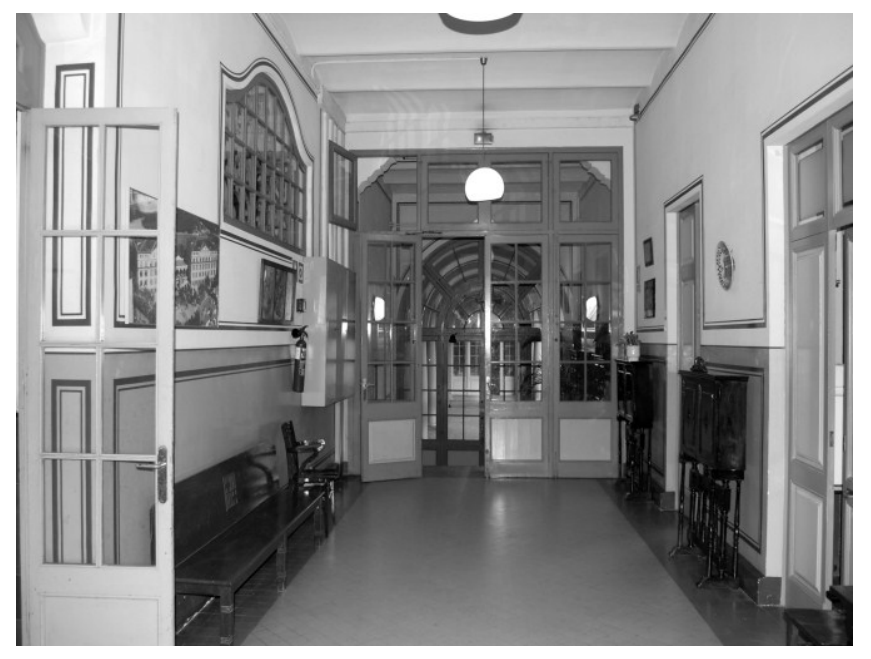

Hist. Educ. [Online]

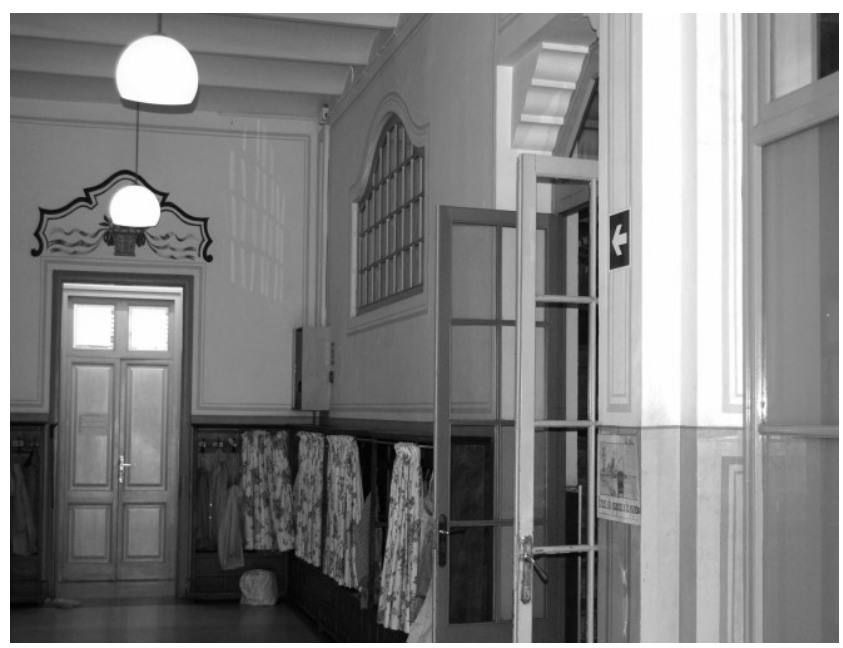

ก. 46

Maio/ago., 2015

p. $187-199$ 
A primeira tipologia, denominada Mobiliário de inspiração renascentista e barroca, tem como característica a referência aos móveis castelhanos e catalães do século 16 e 17 e corresponde, cronologicamente, a primeira etapa de atuação do arquiteto frente à Comissão de Cultura (1917-1923). Goday conhecia as características formais e construtivas desde tipo de mobiliário, graças ao seu trabalho anterior na Junta de Museus $^{12}$, mas também por suas viagens ao exterior. Fazem parte desta etapa o armário da direção do Grupo Escolar Casas e a Biblioteca Escolar Circulante do Grupo Escolar Ramon Llull - figura 4.

Figura 4 -

Projeto para armário da direção e foto de época da biblioteca escolar circulante.

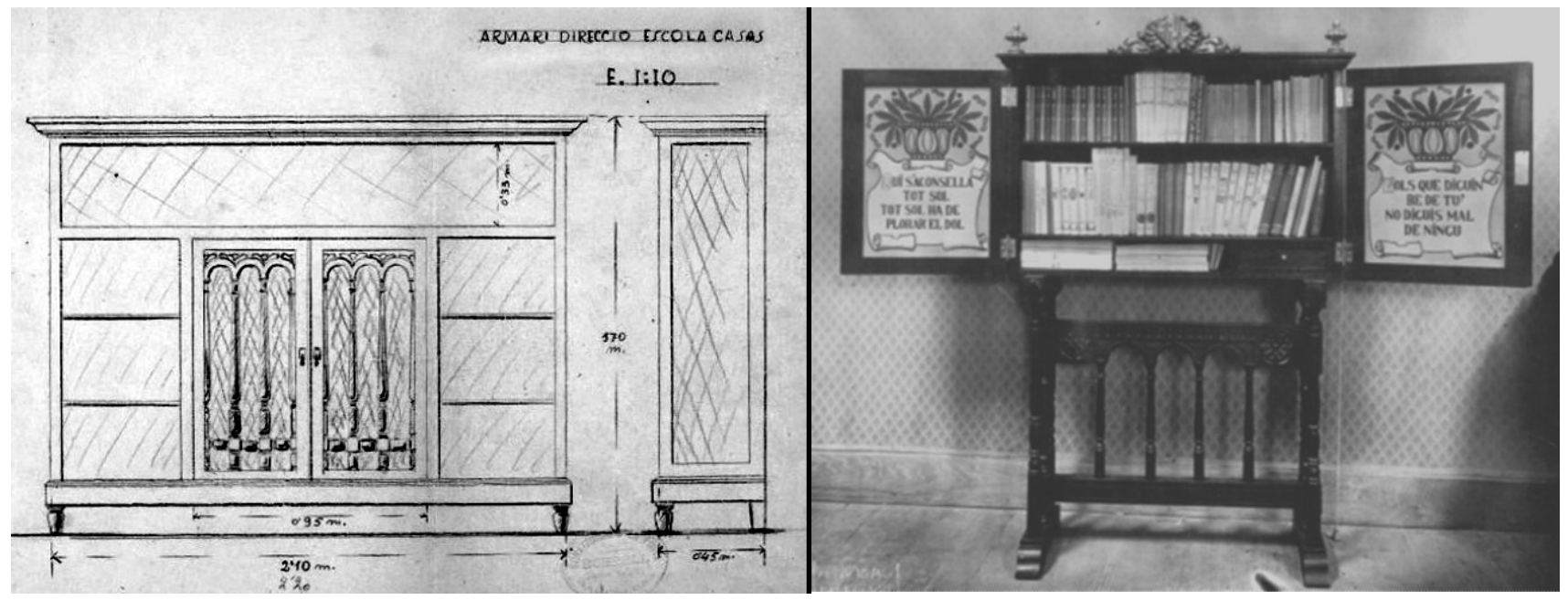

Fonte: Pascual, 2009, p. 12 e 15.

O primeiro móvel é um armário para guardar material de expediente e os pertences da pessoa da direção. Inspirado nos armários do século 17, era confeccionado em madeira torneada e encaixada, tingida e envernizada, nas dimensões de $174 \times 232 \times 51$ $\mathrm{cm}$. O segundo móvel, é um exemplo da preocupação do arquiteto com as necessidades próprias das escolas. Projetado em 1921, trata-se de um móvel para guardar livros e revistas, idealizado para realizar as funções de uma pequena biblioteca. Goday tomou como modelo as arquimesas castelhanas do século 17 e projetou um tipo de mobiliário com grande capacidade (Pascual, 2008).

Mobiliário de inspiração popular, a segunda tipologia, corresponde a uma evolução da primeira ao estilo mais funcional e simples. Aparece a partir de 1924 e se mantém até o final da trajetória do arquiteto. Foram estas formas, inspiradas no repertório tradicional, que abriram o caminho para formas racionalistas, tal como poderemos observar na seguinte tipologia. Esse caminho começou a ser traçado pela Exposição Internacional do Móvel e de Decoração de Interiores, celebrada em Barcelona em 1923. Dois anos mais tarde um concurso promoveu a criação de mobiliário de qualidade acessível para as classes obreiras e, na exposição organizada ao final do concurso, se mostraram três peças de mobiliário escolar.

${ }^{12}$ Cabe recordar que entre os anos 1909 y 1918, com a colaboração de Josep Goday, Josep Puig i Cadafalch, arquiteto, historiador de arte e político, publicou L'arquitectura românica a Catalunya, um trabalho de inventário geográfico e histórico sobre a arte medieval da Catalunha. Mais detalhes em Barral Altet (2008). 
Segundo Pascual (2008), isso demonstra, além do interesse pelo mobiliário doméstico, que havia também motivação pelo mobiliário escolar, um aspecto que se relaciona diretamente com a criação dos grupos escolares, ou seja, centros públicos para a educação dos filhos dos obreiros. Como exemplo desta etapa, citamos o armário para material do Grupo Escolar Collasso i Gil e o armário para aula do Grupo Escolar Ramon Llull, figura 5. Trata-se de armários de madeira torneada e encaixada, tingida e envernizada, nas dimensões de 175×306×51 cm e 132×297× 30,5cm, respectivamente.

Figura 5 -

Esquerda: armário para material; direita: armário para sala de aula.

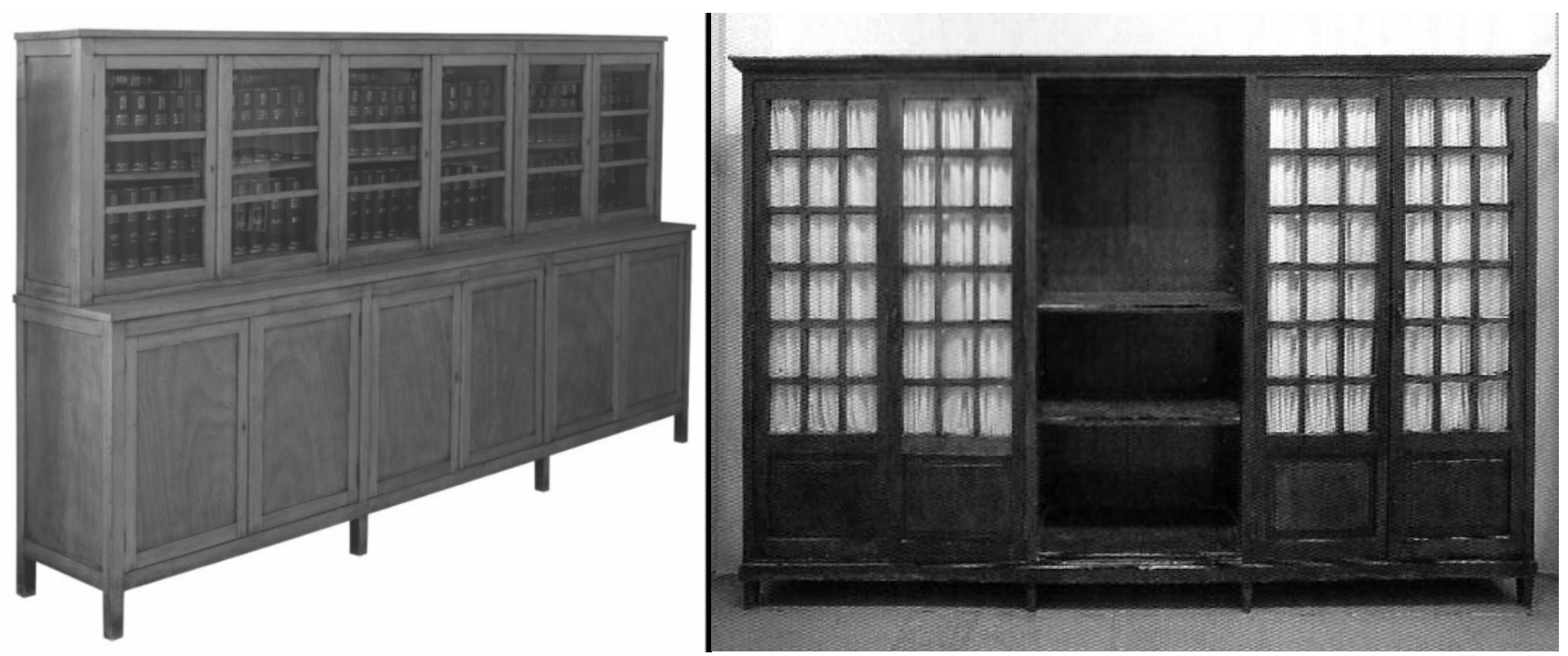

Fonte: Pascual, 2008, p. 345 e 347.

No primeiro caso a superfície lisa de madeira com sua cor natural, têm os pés torneados integrados à estrutura. No segundo, uma tipologia de armário vitrine, fechado com portas com painéis de vidro sobre estrutura de madeira. Goday os projetou para diversos grupos escolares. De forte componente prático e utilitário, suas formas sóbrias e simples são exemplos do mobiliário que nos recordam algumas das características da sua arquitetura.

A terceira etapa, Mobiliário racionalista, aparece no momento em que Goday confirma sua direção ao racionalismo ${ }^{13}$. Este tipo de mobiliário, figura 6 , estava mais direcionado ao Grupo Escolar Collasso i Gil, inaugurado em 1934 e estavam formados por bancos para vestiários, armários para ficheiros e, sobretudo móveis para a direção. Conforme Pascual (2008) cabe entender esta linha como o passo seguinte respeito à evolução formal do grupo de móveis anteriormente tratados, tudo em sintonia com a arquitetura daquela escola. Além dos móveis para os grupos escolares, o arquiteto Josep Goday também projetou móveis para a ala infantil da escola Decroly, possivelmente em 1922, incluindo na proposta, cômodas, cadeiras altas e berços para bebes.

\footnotetext{
${ }^{13}$ Tendência surgida na arquitetura como resposta às necessidades sociais na Europa pós-primeira Guerra Mundial. 
Figura 6 -

Projetos de Goday para móveis da direção do Grupo Escolar Collasso i Gil.
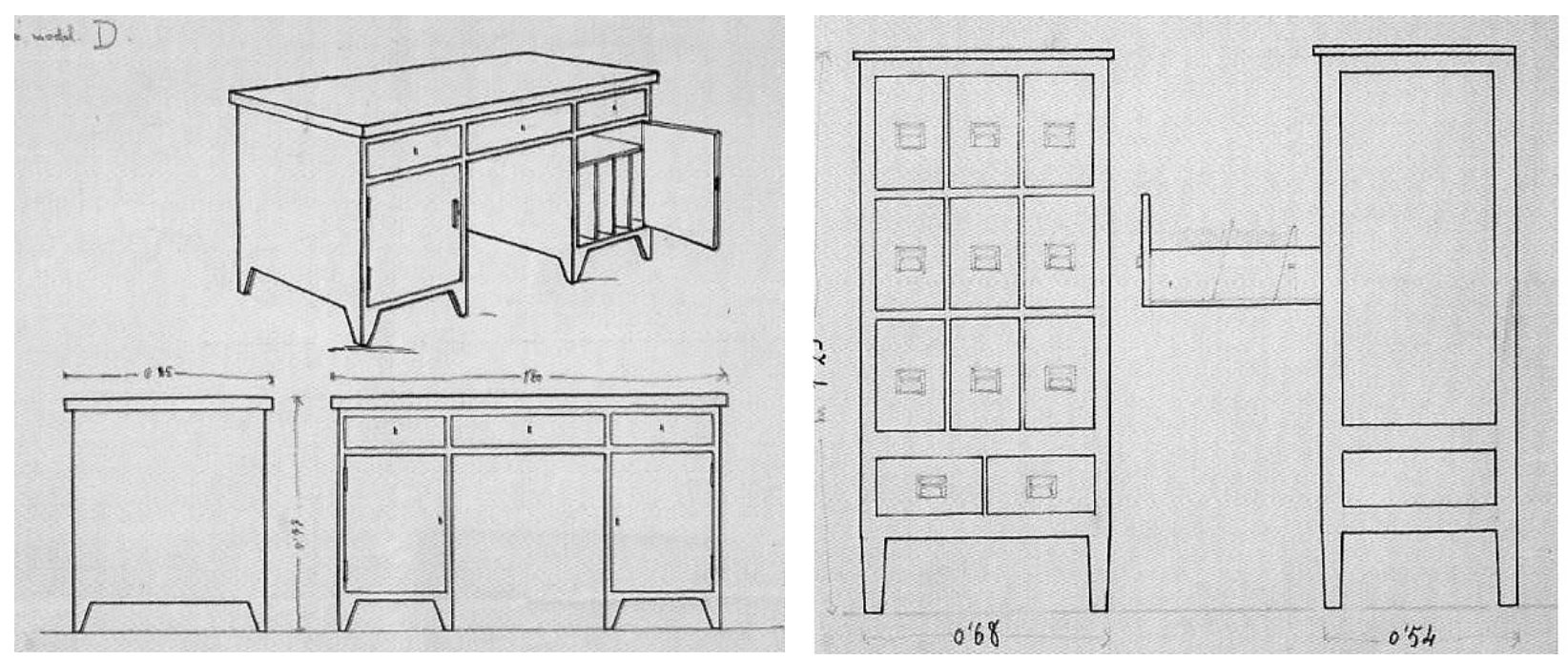

Fonte: Pascual, 2008, p. 345 e 347.

\section{Considerações finais}

$\mathrm{Na}$ união entre a pedagogia de Manuel Ainaud e a arquitetura de Josep Goday foram trilhados os caminhos da moderna pedagogia no município de Barcelona. Pela Assessoria Técnica foi possível a geração de uma arquitetura escolar específica, com a construção de edifícios escolares que cumpriam os requisitos educativos, higiênicos e arquitetônicos para o ensino público na primeira metade do século 20.

Esses intensos intercâmbios repercutiram, além da concepção arquitetônica, também no mobiliário e na decoração. Nas propostas de Goday se revela o grau de controle do arquiteto sobre a obra, seja a respeito do projeto arquitetônico, seja da tipologia e decoração dos ambientes internos. Expôs ainda, seu conhecimento sobre a madeira e outros materiais nos projetos de mobiliário escolar.

Procurei expor nesse artigo um dos principais testemunhos e referentes da arqueologia da escola, a partir do mobiliário projetado pelo arquiteto Josep Goday. Pela diversidade e variedade de elementos, estamos diante de um conjunto que merece um estudo aprofundado, pois recorrendo a outras fontes, como os discursos presentes nas leis, decretos e regulamentos voltados para o ensino público ou jornais e revistas de época, e da própria indústria moveleira, é possível compor um indicador de como a difusão de um projeto pedagógico e a modernização da escola tratavam os usos desses espaços.

\section{Referências}

ABREU JR., Laerthe de Moraes. Apontamentos para uma metodologia em cultura material escolar. Pro-Posições. Campinas, Unicamp, v. 16, n. 1, 2005, p. 145-164.

ABREU JR., Laerthe de Moraes. Por uma metodologia em cultura material educativa: trabalho com documentos sobre educação na primeira metade do século 20. Educação em Perspectiva. Viçosa, v. 3, n. 1, 2012, p. 167-184. 
BENCOSTTA, Marcus Levy. Mobiliário escolar francês e os projetos vanguardistas de Jean Prouvé e André Lurçat na primeira metade do século 20. Educar em Revista. Curitiba: UFPR, n. 49, 2013, p. 19-38.

BERGSON, Henri. Matéria e memória: ensaio sobre a relação do corpo com o espírito. São Paulo: Martins Fontes, 2010.

BOHIGAS, Oriol. Arquitectura y pedagogía, la tradición escolar en Cataluña. Revista Arquitectura Viva, n. 56. Madrid, 1997, p. 17-19.

CHÂTELET, Anne-Marie. Ensaio de historiografia I: a arquitetura das escolas no século 20. Hist. Educ. (Online), Porto Alegre, v. 10, n. 20, 2006, p. 7-38.

CUIXART GODAY, Marc. L'instintd'arquitecte. In: CUBELES BONET, Albert; CUIXART GODAY, Marc (orgs.). Josep Goday Casals - arquitectura escolar a Barcelona: de la Mancomunitat a la República. Barcelona, 2008, p. 139-335.

DOMĖNECH, Salvador Domènech i. Manuel Ainaud i el patronat escolar de Barcelona. Temps d'Educació, Barcelona, n. 17, 1997, p. 273-291.

JULIA, Dominique. A cultura escolar como objeto histórico. Revista Brasileira de História da Educação. São Paulo: SBHE, 2001, p. 9-43.

MARCílIO, Maria Luiza. História da escola em São Paulo e no Brasil. São Paulo: Imprensa Oficial do Estado de São Paulo/Instituto Fernand Braudel, 2005.

PASCUAL, Eva. El mobiliari i la decoració interior de les escoles. In: CUBELES BONET, Albert; CUIXART GODAY, Marc (orgs.). Josep Goday Casals arquitectura escolar a Barcelona: de la Mancomunitat a la República. Barcelona, 2008, p. 337-353.

PASCUAL, Eva. El mobiliario de Josep Goday para las escuelas del Ayuntamiento de Barcelona. Estudi del Moble. Barcelona, n. 9, 2009, p. 8-17. Disponível em $<$ http://www.estudidelmoble.com/LinkClick.aspx?fileticket=qSttcufJfe0\%3D\&tabid=2087\& mid=5855 >. Acesso em 12 jan. 2014.

PERICACHO GÓMEZ, Francisco Javier. Pasado y presente de la renovación pedagógica en España (de finales del Siglo 19 a nuestros días): un recorrido a través de escuelas emblemáticas. Revista Complutense de Educación. Madrid, v. 25, 2014, p. 47-67. Disponível em <http://revistas.ucm.es/index.php/RCED/article/viewFile/43309/41007>. Acesso em 5 abr. 2014.

RÁFOLS, Josep F. Josep Goday, arquitecto de los grupos escolares de Barcelona. Cuadernos de Arquitectura. Barcelona, n. 35, 1959, p. 8-11. Disponível em $<$ http://www.raco.cat/index.php/CuadernosArquitectura/article/view/109271>. Acesso em 12 jun. 2009.

SÁ, Jauri dos Santos. El edificio escolar en el ensanche de Barcelona. Barcelona: UPC. 2012, 408f. Tese (doutorado em Arquitetura). Programa de Pós-Graduação em Arquitetura, Universidade Politécnica da Catalunha.

VIDAL, Diana Gonçalves. Cultura e prática escolares: uma reflexão sobre documentos e arquivos escolares. In: SOUZA, Rosa Fátima de; VALDEMORIN, Vera Teresa (orgs.). A cultura escolar em debate, questões conceituais, metodológicas e desafios para a pesquisa. Campinas: Autores Associados, 2005, p. 3-30.

VIÑAO FRAGO, Antonio. Escolarización, edificios y espacios escolares. Revista Participación Educativa. Madrid: Consejo Escolar del Estado, n 7, 2008, p. 16-27. Disponível em <http://www.mecd.gob.es/revista-cee/pdf/n7-vinao-frago.pdf>. Acesso em 5 jun. 2009. 
VIÑAO FRAGO, Antonio. La historia material e inmaterial de la escuela: memoria, patrimonio y educación. Educação. Porto Alegre, v. 35, n. 1, 2012, p. 7-17. Disponível em $<$ http://www.redalyc.org/comocitar.oa?id=84823352002>. Acesso em 20 jan. 2014.

JAURI DOS SANTOS SÁ é doutor em Arquitetura pela Universidade Politécnica da Catalunha - Espanha. Atualmente desenvolve estágio pós-doutoral no Programa de Pós-Graduação em Educação da Universidade do Vale do Rio dos Sinos.

Endereço: Rua São Joaquim, 775/601 - 93010-190 - São Leopoldo - RS - Brasil. E-mail: arqjauri@gmail.com.

Recebido em 25 de abril de 2014.

Aceito em 7 de dezembro de 2014. 